\title{
Giant cell arteritis limited to large elastic pulmonary arteries
}

\author{
SJOERD SC WAGENAAR, CEES JJ WESTERMANN, BRYAN CORRIN \\ From the Departments of Pathology and Lung Disease, St Antonius Hospital, Utrecht, The Netherlands, and the \\ Department of Lung Pathology, Cardiothoracic Institute, Brompton Hospital, London
}

Pulmonary arteritis usually affects medium or small muscular vessels and is a well-recognised feature of diseases such as Wegener's granulomatosis, severe pulmonary hypertension, sarcoidosis, lymphomatoid granulomatosis, necrotising sarcoid granulomatosis, and the disseminated form of temporal arteritis. Medium to small sized pulmonary arteries may also be involved in connective tissue disorders such as systemic lupus erythematosus and rheumatoid disease. Takayashu's disease may affect the large elastic pulmonary arteries but vasculitis limited to these vessels is exceptionally rare. This paper reports such a case.

\section{Case report}

On 22 November 1979, a 33-year-old male mechanic complained of sudden pleuritic pain in the right chest, without shortness of breath, cough, or haemoptysis. On 3 November he had experienced discomfort in the right chest during a rapid ascent from a depth of $10 \mathrm{~m}$ while scuba-diving. The discomfort had disappeared quickly after surfacing and he had since dived again without any problems. A chest radiograph on 26 November showed an area of consolidation peripherally in the lateral segment of the right middle lobe.

The patient was admitted to a general hospital and later transferred to St Antonius' Hospital, Utrecht. On admission he appeared healthy and was afebrile. Physical examination revealed decreased breath sounds in the suprahepatic region but was otherwise entirely negative with normal pulses in all peripheral arteries. Radiologically the opacity in the right middle lobe was still apparent. Review of a routine chest film dated May 1979 showed no abnormalities. Bronchography showed delay in the filling of the right middle lobe, but was otherwise unremarkable. Bronchoscopy revealed no abnormalities. Laboratory data showed an ESR of $12 \mathrm{~mm}$ in the first hour, while the haemoglobin, white blood cell and thrombocyte counts, electrolytes, and liver and kidney function tests were all normal. Fibrinogen and fibrinogen split products were also normal, as were immunoglobulins, antistreptolysin titre, rheumatoid and antinuclear factors, LE-tests, cold agglutinins, and serological studies for the common respiratory viruses, fungi, and toxo-

Address for reprint requests: Professor B Corrin, Department of Pathology, Cardiothoracic Institute, Brompton Hospital, Fulham Road, London'SW3 6HP.

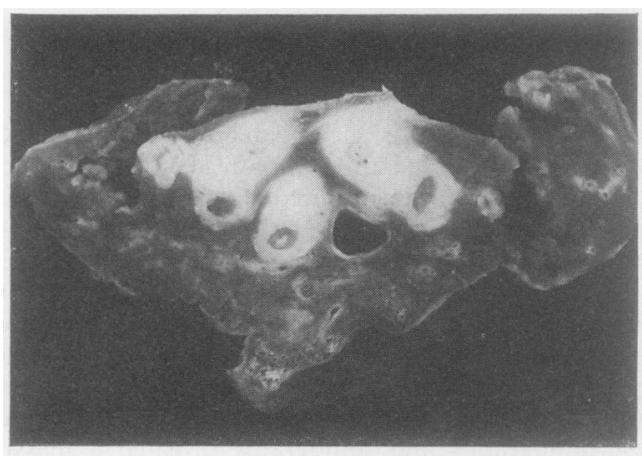

Fig 1 The resected middle lobe showing thickened and occluded hilar arteries, with recanalisation. $\times 0.6$.

plasmosis. A Mantoux test was negative. Examination of $\frac{3}{3}$ sputum and bronchial aspirate and a fibroptic biopsy of the right middle lobe bronchus revealed no pathogens or: malignant cells. Pulmonary function tests were normal. Pulmonary artery pressure, and arterial and mixed venous 0 blood gases at rest and after exercise were also normal. Lung scans showed a perfusion defect in the region of the right middle lobe. Pulmonary arteriography showed that 3 the diameter of the right middle lobe arteries was de-i creased. Phlebographic studies of the iliac-femoral system $\frac{\text { 의 }}{3}$ were normal. There was no evidence of pulmonary embolism or of a generalised arteritis, but the perfusion음 defect persisted and the patient therefore underwent $>$ operation on 2 February 1980 . During surgery a softo tumour was felt in the right middle lobe. The middle lobe was resected.

Examination of the excised middle lobe showed oc- $N$ cluded and partly recanalised lobar and segmental arteries in the hilar region (fig 1) with infarction in the distal lung. $\frac{\omega}{6}$ These findings were confirmed microscopically. The elastic arteries showed organised thrombus, extensive fragmentation of the elastic laminae, proliferation of fibroblasts and capillaries, and a severe mononuclear in $-?$ flammation with numerous multi-nucleated giant cellso related to the fragmented elastic laminae (fig 2). Dense0 perivascular fibrosis suggested that the process was of at涫 least one month's duration. Muscular pulmonary苚 arteries, pulmonary veins, and bronchial arteries were not affected. 


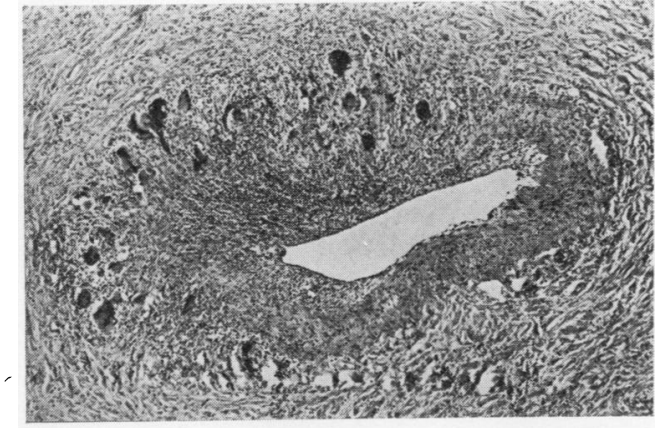

(a)

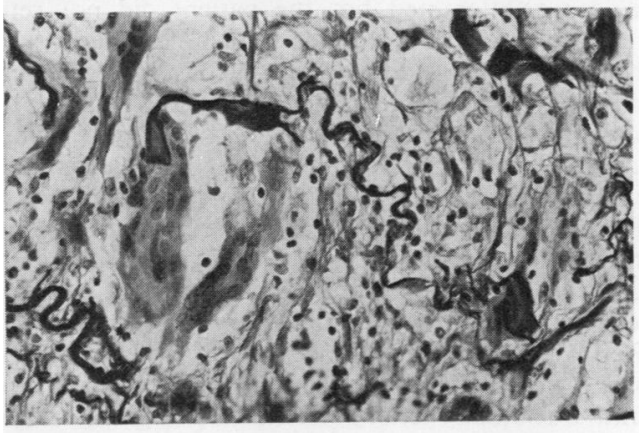

(b)

Fig 2 (a) Severe giant cell arteritis with narrowing of the lumen and perivascular fibrosis. Haematoxylin and eosin, $\times 22$. (b) Giant cells related to elastic laminae. Elastin van Gieson, $\times 175$.

Recovery since the operation has been uneventful. A perfusion lung scan on 26 June 1980 showed no abnormalities in the remaining lung tissue. Nine months after the operation the patient is well without further treatment

\section{Discussion}

Giant cells may be found in several forms of pulmonary arteritis but the large numbers seen in the present case, together with the absence of discrete sarcoid granulomas, limit consideration to Takayashu's disease and the disseminated form of "temporal" arteritis (in which temporal involvement may be absent). Both of these diseases may affect the pulmonary arteries ${ }^{1-3}$ but we know of no reports of either confined to the lungs. Although "temporal" arteritis and Takayashu's disease are both forms of giant cell arteritis and are evidently closely related, there are features by which they may be distinguished." Temporal arteritis is typically a disease of the elderly which affects muscular arteries, whereas Takayashu's disease usually affects young adults and large elastic arteries. Although our patient is young and the vessels affected are large elastic arteries, the giant cell infiltration is particularly florid and we therefore prefer not to categorise his disease into any particular type of giant cell arteritis. The exceptional feature in this case is that the disease appears to be confined to the lesser circulation. Note must be taken of the discomfort our patient experienced while diving a few weeks before the onset of his main illness but a definite causal relationship is unproven.

\section{References}

${ }^{1}$ Klein RG, Hunder GG, Stanson AW, Sheps SG. Large artery involvement in giant-cell (temporal) arteritis. $A n n$ Intern Med 1975;83:806-12.

2 Lupi-Herrera E, Sanchez-Tores G, Marcushamer J, Mispireta J, Horwitz S, Vela JE. Takayasu's arteritis. Clinical study of 107 cases. Am Heart J 1977;93:94-103.

${ }^{3}$ Lie JT. Disseminated visceral giant cell arteritis: a new pathologic entity? Am J Clin Pathol 1977;67:213.

4 Fauci AS, Haynes BF, Katz P. The spectrum of vasculitis. Ann Intern Med 1978;89:660-76. 